\title{
Perbandingan Kadar Kolesterol pada Guru Obes dan Non-Obes di SMP Negeri I dan II Kauditan Minahasa Utara
}

\author{
${ }^{1}$ Hizkia Rumampuk \\ ${ }^{2}$ Diana V. D. Doda \\ ${ }^{2}$ Hedison Polii
}

\author{
${ }^{1}$ Program Studi Pendidikan Dokter Fakultas Kedokteran Universitas Sam Ratulangi Manado \\ ${ }^{2}$ Departemen Fisiologi Universitas Sam Ratulangi Manado \\ Email: hizkia.rumampukyahoo.com
}

\begin{abstract}
To date, obesity incidence is increasing globally in developing and developed countries. Increased prevalence of obesity suggests that there is an increased risk of obesityrelated illnesses. Metabolic and lipid transport disorders can lead to hypercholesterolemia. This can happen especially among people with less physical activity, such as teacher. This study was aimed to assess the comparison of cholesterol levels in obese and non-obese teachers. This was an analytical descriptive study with a cross-sectional design. Respondents were 35 teachers at SMP Negeri I and II (junior high school) Kauditan Kabupaten Minahasa Utara consisting of 26 females and 9 males. Body mass index (BMI) was calculated and fasting cholesterol levels were checked from peripheral blood using autocheck tool. The results showed that there were 16 (45.7\%) non-obese respondents and 19 (54.3\%) obese respondents. Of the 35 respondents, 24 (68.6\%) had normal cholesterol levels and 11 (31.4\%) had hypercholesterolemia. The bivariate analysis using Mann Whitney test revealed that there was no significant difference in cholesterol levels between obese and non-obese teachers $(P=$ 0.537). Conclusion: There was no significant difference in cholesterol levels between obese and non-obese teachers at SMP Negeri I and II Kauditan Kabupaten Minahasa Utara.
\end{abstract}

Keywords: cholesterol level, BMl, teachers

\begin{abstract}
Abstrak: Insiden obesitas dilaporkan tetap mengalami peningkatan secara global, baik di negara berkembang maupun negara maju. Peningkatan prevalensi obesitas ini memberikan informasi bahwa terdapat peningkatan risiko penyakit yang terkait obesitas. Gangguan metabolism dan transportasi lipid bisa mengakibatkan hiperkolesterolemia. Hal ini bisa terjadi pada orang yang kurang aktif secara fisik, antara lain guru. Penelitian ini bertujuan untuk membandingkan kadar kolesterol guru yang obes dan tidak obes. Jenis penelitian ialah deskriptif analitik dengan desain potong lintang. Responden ialah 35 orang guru di SMP Negeri I dan II Kauditan Kabupaten Minahasa Utara, terdiri dari 26 perempuan dan 9 laki-laki. Indeks masa tubuh (IMT) dihitung dan kadar kolesterol puasa diperiksa dari darah perifer menggunakan alat autocheck. Analisis bivariat menggunakan Mann Whitney dengan nilai signifikan $P \leq 0,05$. Hasil penelitian mendapatkan $16(45,7 \%)$ responden non-obes dan 19 $(54,3 \%)$ responden obes. Kadar kolesterol normal pada $24(68,6 \%)$ responden dan hiperkolesterolemia pada $11(31,4 \%)$ responden. Anilisis bivariat menggunakan uji Mann Whitney menunjukkan tidak terdapat perbedaan bermakna pada kadar kolesterol antara guru obes dan non-obes $(P=0,537)$. Simpulan: Tidak terdapat perbedaan bermakna pada kadar kolesterol antara guru obes dan non-obes di SMP Negeri I dan II Kauditan Kabupaten Minahasa Utara.
\end{abstract}

Kata kunci: kadar kolesterol, IMT, guru 
Obesitas merupakan suatu kelainan kompleks pengaturan nafsu makan dan metabolism energy yang dikendalikan oleh beberapa faktor seperti genetik, aktifitas fisik, perilaku. ${ }^{1}$ Insiden obesitas dilaporkan tetap mengalami peningkatan secara global, baik di negara berkembang maupun negara maju. Di Indonesia peningkatan. prevalensi kelebihan berat badan terjadi baik pada wanita dan pria, Sulawesi Utara menduduki pringkat pertama nasional $(40,54 \%)$ diikuti Kalimantan Timur $(35,38 \%)$ dan DKI Jakarta $(34,67 \%))^{2,3}$

Obesitas dapat diketahui dengan mengukur indeks masa tubuh (IMT) dan sering dikaitkan dengan gangguan parameter lipid darah (dislipidemia) seperti hipo atau hiperkolesterolemia. Beberapa hasil penelitian di negara maju menyatakan kadar kolesterol total meningkat seiring dengan meningkatnya IMT, dimana obesitas merupakan salah satu hal yang bisa didapatkan dari penghitungan IMT, namun, beberapa studi juga masih menunjukan hasil yang bertentangan dengan konsensus umum di atas. ${ }^{4}$

Di Indonesia, penelitian tentang hubungan IMT/obesitas dan kadar kolesterol juga masih memberikan hasil yang bervariasi. Nugraha et al. $^{5}$ meneliti 96 responden sehat di Surakarta dan menyimpulkan bahwa tidak terdapat hubungan IMT dengan kadar kolesterol total. Sitepu ${ }^{6}$ meneliti 93 responden di rumah sakit dan juga mendapatkan hasil yang tidak bermakna. Hasil penelitian oleh Ercho et al. ${ }^{7}$ di Lampung menunjukkan bahwa terdapat hubungan bermakna antara obesitas dengan kadar High Density Lipoprotein (HDL) dan Low density Lipoprotein (LDL). Penelitian tentang hubungan kolesterol dan IMT telah cukup banyak dipublikasi namun penelitian yang membandingkan kadar kolesterol pada sampel yang obes dan non-obes masih terbatas. Hal ini memberikan ruang yang masih luas untuk melakukan penelitian dalam bidang terkait.

Guru melaksanakan beban kerjanya di hari sekolah selama 8 jam atau 40 jam seminggu. Studi dari Retamal MEC di New Zealand menyatakan aktifitas fisik okupasi guru bisa dikategorikan sedang. Namun, pekerjaan guru dengan tugas terkait kewajiban guru seperti memeriksa pekerjaan rumah dan melakukan persiapan mengajar, yang biasanya dilakukan sesudah jam sekolah mengakibatkan terjadi pengurangan waktu luang guru untuk melakukan aktivitas fisik sehingga membuat guru lebih mudah mengalami berat badan berlebih dan obesitas..$^{8-10}$

Tujuan penelitian ini ialah untuk mengetahui perbandingan kadar kolesterol total pada guru yang obes dan non-obes di SMP Negeri I dan II Kauditan Kabupaten Minahasa Utara, serta mengevaluasi gambaran IMT dan kadar kolesterol para guru tersebut.

\section{METODE PENELITIAN}

Jenis penelitian ini ialah deskriptif analitik dengan desain potong-lintang pada guru SMP Negeri I dan II Kauditan Minahasa Utara pada bulan SeptemberOktober 2017. Sampel dipilih secara purposive sampling. Yang memenuhi kriteria dan bersedia ikut dalam penelitian ini, diukur tinggi badan dan berat badannya serta diperiksa kadar kolesterol darah dengan Alt autocheck. Data kemudian diolah dan dianalisis dengan menggunakan Microsoft Excell dan Statistical Package and Social Science (SPSS).

\section{HASIL PENELITIAN}

Karakteristik umum dari 35 responden sebagai berikut: 9 (25,7\%) laki-laki dan 26 (74,3\%) perempuan. Indeks Masa Tubuh $\geq$ 27 didapatkan pada $19(54.3 \%)$ responden dan kadar kolesterol $\geq 200 \mathrm{mg} /$ dLberjumlah 11 responden $(31,4 \%)$ (Tabel 1$)$.

Kadar kolesterol tertinggi berdasarkan jenis kelamin dan IMT didapatkan pada perempuan obes berjumlah 13 orang (37\%) dengan kadar rerata kolesterol 211,8 mg/dL sedangkan kadar paling rendah pada kelompok laki-laki non-obes $127 \mathrm{mg} / \mathrm{dl}$ (Tabel 2). Gambar 1 memperlihatkan kadar kolesterol pada kelompok obes dan nonobes berdasarkan jenis kelamin. 
Tabel 1. Gambaran umum responden

\begin{tabular}{lcc}
\hline Variabel & Jumlah & $(\%)$ \\
\hline Jenis kelamin & & \\
Laki-laki & 9 & 25,7 \\
Perempuan & 26 & 74,3 \\
Total & 35 & 100 \\
\hline Usia & & \\
Remaja akhir (17-25 ) & 4 & 11,4 \\
Dewasa awal (26-35) & 4 & 11,4 \\
Dewasa akhir (36-45) & 11 & 31,4 \\
Lansia awal (46-55) & 13 & 37,2 \\
Lansia akhir (56-65) & 3 & 8,6 \\
Total & 35 & 100 \\
\hline IMT & & \\
$<27$ & 15 & 42,9 \\
$\geq 27$ & 20 & 57,1 \\
Total & 35 & 100 \\
\hline Kadar kolesterol & & \\
$<200$ mg/dL & 24 & 68,6 \\
$\geq 200$ mg/dL & 11 & 31,4 \\
Total & 35 & 100 \\
\hline
\end{tabular}

Responden terbanyak menurut kelompok obes dan non-obes terdapat pada kelompok lanjut usia (lansia) awal kelompok obes, sedangkan yang paling sedikit pada usia lansia akhir yang hanya berjumlah 1 orang pada kelompok yang sama. Secara keseluruhan responden lansia awal paling banyak yaitu 13 orang dan paling sedikit lansia akhir 3 orang. Berdasarkan kategori usia, pada kelompok non-obes kadar kolesterol tertinggi pada usia 36-45 tahun yaitu 189,4 mg/dL, demikian juga kelompok obes pada usia yang sama dengan kadar kolesterol 198,3mg/dL (Tabel 3).

Analisis statistik menunjukkan tidak terdapat perbedaan bermakna pada perbandingan kadar kolesterol responden yang obes maupun non-obes pada guru di SMP Negeri I dan II Kauditan Kabupaten Minahasa Utara. Hasil analisis menunjukkan $P=0,631 \quad(P>0,05)$ yang berarti tidak terdapat perbedaan bermakna rerata kadar kolesterol pada kedua kelompok, baik nonobes maupun obes. Hal ini menunjukkan bahwa kadar kolesterol tidak berbeda nyata pada responden dengan IMT normal atau obesitas.

Tabel 2. Distribusi frekuensi jenis kelamin responden dan kadar kolesterol rata-rata

\begin{tabular}{lcccc}
\hline Kategori & $\begin{array}{c}\text { Laki-laki } \\
\mathbf{n}(\boldsymbol{\%})\end{array}$ & MKK & $\begin{array}{c}\text { Perempuan } \\
\mathbf{n}(\boldsymbol{\%})\end{array}$ & MKK \\
\hline Non-obes & $2(5,7 \%)$ & 127 & $14(40 \%)$ & 198.7 \\
Obes & $6(17,1)$ & 130.8 & $13(37 \%)$ & 211.8 \\
Total & $8(22,85)$ & & $27(77,1 \%)$ & \\
\hline
\end{tabular}

MKK, Mean Kadar Kolesterol

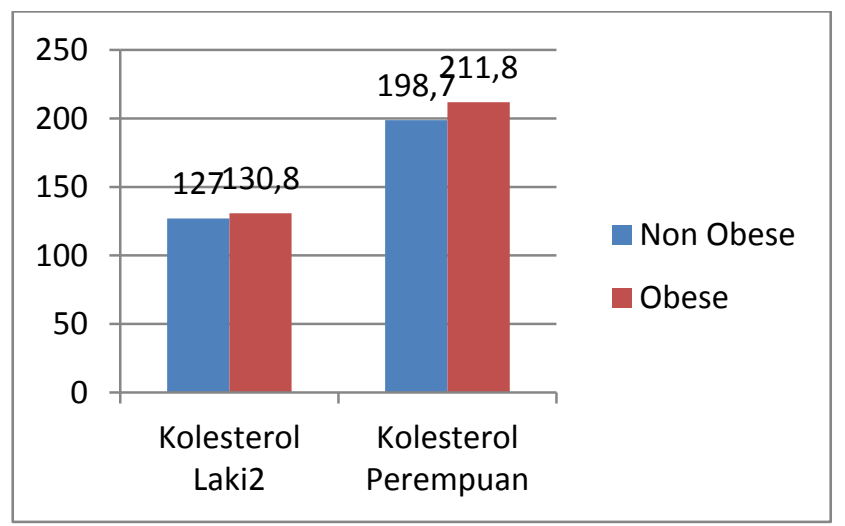

Gambar 1. Kadar kolesterol pada laki-laki dan perempuan obes dan non-obes 
Tabel 3. Distribusi frekuensi usia responden

\begin{tabular}{lcccc}
\hline Kategori usia (tahun) & \multicolumn{2}{c}{ Non-obes } & \multicolumn{2}{c}{ Obes } \\
\cline { 2 - 5 } & $\mathrm{n}(\%)$ & $\begin{array}{c}\text { Kadar } \\
\text { kolesterol } \\
(\mathrm{mg} / \mathrm{dL})\end{array}$ & $\mathrm{n}(\%)$ & $\begin{array}{c}\text { Kadar } \\
\text { kolesterol } \\
(\mathrm{mg} / \mathrm{dL})\end{array}$ \\
\hline Remaja akhir (17-25) & $4(11,4)$ & 186,5 & 0 & - \\
Dewasa awal (26-35) & $2(5,7)$ & 167,5 & $2(5,7)$ & 135.5 \\
Dewasa akhir (36-45) & $5(14,3)$ & 189,4 & $6(17,1)$ & 198.3 \\
Lansia awal (46-55) & $3(8,6)$ & 181,7 & $10(28,6)$ & 193.3 \\
Lansia akhir (56-65) & $2(5,7)$ & 175 & $1(2,9)$ & 145 \\
Total & $16(45,7)$ & & $19(54,3)$ & \\
\hline
\end{tabular}

Tabel 4. Hasil Analisa Statistik

\begin{tabular}{lc}
\hline & $\begin{array}{c}\text { Kadar } \\
\text { kolesterol }\end{array}$ \\
\hline Mann-Whitney U & 131.500 \\
Wilcoxon W & 341.500 \\
Z & -.617 \\
Asymp. Sig. (2-tailed) & .537 \\
Exact Sig. [2*(1-tailed Sig.)] & $.542^{\mathrm{b}}$ \\
\hline
\end{tabular}

\section{BAHASAN}

Jumlah responden pada penelitian ini sebesar 35 orang guru, sebagian besar ialah perempuan $(74,3 \%)$. Usia terbanyak di kelompok lanjut usia awal (46-55 tahun) sebanyak $37,2 \%$ dan dari total sampel, 54,3 $\%$ merupakan responden yang obes. Kadar kolesterol paling banyak berada dalam kategori normal $(<200 \mathrm{mg} / \mathrm{dL})$ yaitu $68,5 \%$. Jumlah guru perempuan di kedua sekolah tempat penelitian sekitar $75 \%$, sehingga responden perempuan lebih banyak daripada laki-laki dalam penelitian ini. Jumlah responden terbanyak yang mengalami obesitas berusia 46-55 tahun atau pada kategori lansia awal. Hal ini sesuai dengan bertambahnya usia manusia akan lebih mudah mengalami obesitas. ${ }^{4}$

Analisis univariat terkait kadar kolesterol rerata didapatkan bahwa kadar kolesterol rerata tertinggi pada kelompok lakilaki dan perempuan yang obes. Hal ini menunjang banyak penelitian terdahulu bahwa konsentrasi kolesterol darah meningkat seiring dengan meningkatnya berat badan seseorang. Hubungan antara obesitas dan tingginya kadar kolesterol darah telah dilaporkan pada beberapa penelitian terdahulu. ${ }^{4,7}$ Yuliana et al. ${ }^{11}$ menyatakan bahwa obesitas berhubungan dengan abnormalitas kolesterol dalam darah yaitu meningkatnya kolesterol dalam darah pada usia lebih dari 30 tahun. Shah et al. ${ }^{12}$ melaporkan hasil penelitiannya di Pakistan antara kedua kelompok masyarakat (obes dan non-obes) yang menunjukkan bahwa kadar kolesterol total tinggi > $200 \mathrm{mg} / \mathrm{dL}$ terdapat pada kelompok yang obes $(37 \%)$ sedamgkan kelompok yang non-obes lebih rendah (29\%). Hal ini menunjukkan bahwa kadar kolesterol total tinggi cenderung dialami oleh masyarakat yang obes.

Hiperkolesterolemia pada penelitian ini hanya ditemukan pada kelompok perempuan yang obes. Obesitas dalam banyak artikel dihubungkan dengan dislipidemia termasuk peningkatan kolesterol plasma, hipertrigliseridemia, penurunan kolesterol HDL, dan peningkatan partikel LDL. ${ }^{13}$ Kamso et al. melakukan penelitian terhadap 656 responden di 4 kota besar di Indonesia (Jakarta, Bandung, Yogyakarta, dan Padang) dan mendapatkan bahwa prevalensi dislipidemia lebih banyak didapatkan pada perempuan $(56,2 \%)$ dibandingkan pada laki-laki (47\%). Perempuan yang mengidap dislipidemia tersebut ditemukan prevalensi dislipidemia terbesar pada rentang usia 55-59 tahun (rerata 62,1 tahun). ${ }^{14}$

Secara fisiologi hal ini bisa dipahami 
karena penurunan kadar estrogen di usia menopause dapat menyebabkan meningkatnya faktor risiko arteroskleroris akibat meningkatnya kadar kolesterol total, trigliserid dan kolesterol LDL, dan menurunnya kadar kolesterol HDL darah yang bersifat kardioprotektif. Healthy Women Study menyatakan bahwa pada hampir setiap perempuan mengalami peningkatan kolesterol pada waktu menopause. $^{15}$

Hasil penelitian ini menunjukan bertambahnya usia tidak otomatis diikuti dengan bertambahnya kadar kolesterol total baik di kelompok obes maupun non- obes. Hal ini tidak sejalan dengan beberapa penelitian terdahulu. Gostynski et al. ${ }^{4}$ melaporkan suatu analisis mengenai hubungan total kolesterol, usia, dan IMT antara laki-laki dan perempuan dalam proyek World Health Organization, Multinational monitoring of trends and determinants in cardiovascular disease (MONICA) yang dimulai awal tahun 1980s di banyak pusat kesehatan di dunia untuk memonitor pola penyakit kardiovaskuler serta faktor risiko yang terjadi di populasi selama kurang lebih 10 tahun. Pada analisis tersebut dinyatakan bahwa konsentrasi kolesterol darah meningkat sesuai usia, serta hubungan usia dan prevalensi hiperkolesterolemia ini lebih menonjol pada perempuan dibandingkan laki-laki.

Perbedaan hasil yang ditemukan pada penelitian ini bisa disebabkan oleh perbedaan budaya dan pola hidup antara negara Barat yang sudah berkembang dengan tempat penelitian yang dilakukan di Sulawesi Utara, Indonesia. Populasi penelitian MONICA juga merupakan populasi umum sementara penelitian ini terbatas pada populasi guru.

Hasil analisa bivariat dengan menggunakan Mann Whitney, menunjukan bahwa secara statistik tidak terdapat kemaknaan pada perbandingan kolesterol guru yang obesitas dan non obesitas. Penelitian yang dilakukan Yuliana et al. ${ }^{11}$ juga mendapatkan hasil yang sama pada peneltian mereka bahwa tidak ada perbedaan kadar kolesterol antara orang yang obes dan non-obes dimana rerata kadar kolesterol orang yang obes ialah 188,89 mg/dL sedangkan rerata kadar kolesterol orang yang non-obes ialah $190,11 \mathrm{mg} / \mathrm{dL}$. Hasil T test menunjukkan bahwa nilai $\mathrm{t}$ hitung $=0,932(>0,05)$ yang menunjukkan bahwa kedua kelompok identik (tidak ada perbedaan). ${ }^{11}$

Hasil peneltiian yang sedikit berbeda ditemukan oleh Setiono ${ }^{14}$ yang menganalisis dislipidemia pada obesitas dan tidak obesitas di RSUP dr. Kariadi dan Laboratorium klinik swasta di kota Semarang. Hipertrigliseridemia dan hipoHDL pada jenis kelamin laki-laki antara obes dan tidak obes didapatkan perbedaan bermakna sedangkan hiperko-lesterolemia, hipo-HDL pada jenis kelamin perempuan, hiper-LDL, dislipidemia cam-puran antara obes dan tidak obes didapatkan perbedaan yang tidak bermakna.

Beberapa peneltian yang menjadi acuan sebagian besar melaporkan bahwa tidak terdapat perbedaan bermakna antara kadar kolesterol kelompok obes dan nonobes. Hal ini menegaskan bahwa banyak faktor yang memengaruhi kadar kolesterol seseorang dan bukan semata mata dari IMT. Faktor predisposisi yang telah teridentifikasi sebagai penyebab hiperlipidemia antara lain: genetic, usia, jenis kelamin, diet, aktivitas fisik, gaya hidup, penggunaan obat, dan tingkat stres tinggi. ${ }^{14}$ Dengan demikian penelitian yang lebih lanjut dengan memperhatikan factor-faktor predisposisi di atas masih perlu dikembangkan.

Limitasi penelitian ini ialah tidak megikutsertakan data pola makan sehingga tidak diketahui pola makan responden yang obes dan non-obes yang dapat memengaruhi kadar kolesterol yang didapatkan.

Mengenai jumlah responden, sekalipun sudah beberapa kali ke tempat peneltian karena beberapa alasan seperti responden tidak puasa, takut diambil darah untuk diperiksa, dan di SMP Negeri 2 terdapat sekolah siang sehingga guru yang hadir pagi hari sangat terbatas dan yang bersedia didatangi di rumah tidak banyak. 


\section{SIMPULAN}

Berdasarkan hasil penelitian dapat disimpulkan bahwa tidak terdapat perbedaan bermakna pada kadar kolesterol guru yang obes dan non-obes di SMP Negeri I dan II Kauditan Kecamatan Kauditan Minahasa Utara.

\section{SARAN}

Disarankan untuk melakukan penelitian lebih lanjut dengan melibatkan jumlah sekolah dan guru yang lebih banyak.

Disarankan kepada para guru untuk mencapai IMT yang normal melalui upaya diet atau menambah aktifitas fisik regular.

Penelitian selanjutnya sebaiknya harus lebih memperhatikan variabel perancu (stres, aktivitas fisik, dan riwayat penyakit).

\section{Ucapan terima kasih}

Ditujukan kepada para guru SMP Negeri I dan II Kauditan Minahasa Utara yang sudah bersedia menjadi responden penelitian ini serta semua pihak yang ikut membantu penyelesaian penelitian ini.

\section{DAFTAR PUSTAKA}

1. Sugondo S. Obesitas. In: Sudoyo A, Setiyohadi B, Alwi I, Simadibrata KM, Setiati S, editors. Buku Ajar Ilmu Penyakit Dalam Jilid III (5th ed). Jakarta: Interna Publishing, 2010.

2. Badan Penelitian dan Pengembangan Kesehatan Kementerian Kesehatan RI, Riset Kesehatan Dasar 2013

3. Kementrian Kesehatan Republik Indonesia, Profil Kesehatan Indonesia Tahun 2013

4. Gostynski M, Gutzwiller F, Kuulasmaa K, Doring A, Ferrario M, Grafnetter D, Pajak A, Analysis of the relationship between total cholesterol, age, body mass index among males and females in the WHO MONICA Project. Int J Obes. 2004;28:1082-90.

5. Nugraha, Widyatmoko S, Lestari $N$. Hubungan indeks massa tubuh dengan kadar kolesterol total pada guru dan karyawan SMA Muhammadiyah 1 Dan 2 Surakarta [Skripsi]. Surakarta:
Universitas Muhammadiyah; 2014.

6. Sitepu IW. Hubungan antara indeks massa tubuh dengan kadar profil lipid pada pasien dewasa di Bagian Penyakit Dalam Rumah Sakit PHC Surabaya [Skripsi]. Surabaya: Univeristas Katolik Widya Mandala; 2014.

7. Ercho NC, Berawi K, Susantiningsih T. Hubungan obesitas dengan kadar LDL dan HDL pada mahasiswa preklinik Fakultas Kedokteran Universitas Lampung tahun 2013 [Skripsi]. Lampung: Universitas Lampung; 2013.

8. Peraturan menteri Pendidikan Dan Kebudayaan Republik Indonesia nomor 23 tentang hari sekolah, tahun 2017.

9. Retamal MEC. Teachers workplace: physical activity and sedentary behavior [Disertation]. New Zealand: Auckland Universitas of Technology; 2013.

10. Cheung PYP, Chow BC. Association of school teacher occupational and daily physical activity level in Hong Kong. Int J Sport Health Sci. 2012;10:23-9.

11. Yuliana DH, Gabena S, Hasibuan $Y$. Perbandingan kadar kolesterol pada pegawai dengan obesitas dan non obesitas di Poltekkes Kemenkes Medan, Jurnal Ilmiah Pannmed. 2015;10(2):1805.

12. Shah SZA, Devrajani BR, Devrajani T, Bibi I. Frequency of dyslipidemia in obesity versus nonobesity in relation to body mass index (BMI), waist hip ratio (WHR) and waist circumference (WC). Pakistan J Sci. 2008;62(1):27-31,

13. Singh AK, Singh $S$ K, Singh N, Agrawal $\mathbf{N}$, Gopal K. Obesity and dyslipidemia. Int J Biol Med Res. 2011;2(3):824-8.

14. Setiono LY. Dislipidemia pada obesitas dan tidak obesitas Di RSUP Dr. Kariadi dan Laboratorium Klinik Swasta di Kota Semarang [Skripsi]. Semarang: Universitas Diponegoro; 2012.

15. Aditya $\mathrm{T}$, Sugiarto $\mathrm{Ch}$, Tih $\mathrm{F}$. Perbandingan kadar kolesterol total pada wanita menopause yang rutin olahraga dan tidak rutin olahraga [Skripsi]. Bandung: Universitas Kristen Maranatha; 2014. 